\title{
Prospects for technology assessment in a framework of responsible research and innovation
}

\author{
René von Schomberg ${ }^{1}$
}

\section{Introduction}

I was requested to make a contribution on "the societal need for technology assessment". This request forced me to reflect on the same question as Armin Grunwald when he started to work on his introduction to technology assessment (Grunwald 2010), namely: whether there is some consolidated body of scientific knowledge that could adequately represent the self-understanding of the field "technology assessment". Without such a body of knowledge, it would be very difficult to assess this heterogeneous field on its societal needs. The claims experts make in the field on (often assumed) societal needs for TA seem to vary just as much as the working methods and scientific disciplines involved. Now Armin Grunwald succeeded in turning his "introduction" into a major reference work for the field of technology assessment and thereby creating a consolidated body of knowledge, it seems to me that this would leave me merely with the task to provide some footnotes to his work, if I would choose to describe the societal needs from the perspective of the field itself.

I will, however, proceed by placing technology assessment within the context of a broader societal quest for the "right" impacts of science and technology and the imperative of governmental bodies to make "impact assessments" part and parcel of the planning and justification of their major activities. I will do that from a European perspective. The basis of a systematic use of various assessments and foresight will pave the way for a framework for responsible research and innovation on which I will make a proposal.

In the context of European policy making, technology assessments, ideally, have to merge with other types of impact assessments, now the success or failure of major public policies increasingly depend on anticipated impacts of chosen scientific and technological options. Practically, this merging is taking place,

\footnotetext{
1 Dr. Dr. phil. René von Schomberg (email: Rene.vonschomberg@ec.europa.eu) is at the European Commission, Directorate General for Research. The views expressed here are those of the author and may not in any circumstances be regarded as stating an official position of the European Commission.
} 
both driven by a "policy pull" for impact assessments and by the practice of "assessors" itself. This can be illustrated as follows:

1. The European Commission has to deliver general impact assessments on all its major legislative proposals within the framework for better regulation (European Communities 2006). ${ }^{2}$ The Commission impact assessment follows an integrated approach which was introduced in 2002. This includes also ex-ante impact assessments for the Framework Programmes for Research. These impact assessments include among other, social, environmental and economic impacts. These circumstances also bring in focus the interwovenness of technology assessment with broader impacts: results of technology assessments can and should, namely, feed into impacts assessments of prospective, planned research activities. There is in other words, a certain "policy pull" to merge and use impact assessments of various nature.

2. In the tradition of technology assessment, there has been a preoccupation with assessing the intended and non-intended consequences of the introduction of new technologies. TA practitioners had, in order to be able to deliver such assessments, increasingly to interfere with or work together with academic work relating to other assessment activities such as environmental and sustainability impact assessments. Vice versa, those who were engaged with sustainability assessments or even with public policy evaluation or broad impact assessments of important legislative proposals cannot ignore the role of science and technology and had to turn to the outcomes of technology assessments. In other words, the practices of "assessors" already show a certain interwovenness of the various assessments.

The "policy pull" dimension has, however, a reconfiguring influence on the "type" of impacts we wish to assess. Whereas technology assessments have traditionally addressed the "negative consequences" in terms of risks and adverse effects of technologies, the focus of attention within policy is predominantly to demonstrate potentially positive impacts of future outcomes of public policy including research policy. "Negative impacts" are dealt within the context of broader cost-benefit analysis or within specialized fields of policy, such as risk management and risk assessments. The quest for positive or the "right" impacts

2 "It replaces the previous single-sector type assessments and assesses the potential impacts of new legislation or policy proposals in economic (including competitiveness), social, and environmental fields. It consists of a balanced appraisal of all impacts, and is underpinned by the principle of proportionate analysis, whereby the depth and scope of an impact assessment, and hence the resources allocated to it, are proportionate to the expected nature of the proposal and its likely impacts. Wide-ranging consultation with stakeholders is an integral part of the impact assessment approach" (European Communities, 2006). 
is a much more overarching feature of public policy. ${ }^{3}$ This brings us naturally to the question: what are the "right" impacts and how can policy legitimately pursue this quest for the "right" impacts? The subsequent question is then of course how these impacts should be assessed on the basis of various impact assessments including technology assessments. In the following, I will answer these questions and how they can be tackled within a new framework for responsible research and innovation.

\section{Defining the "right" impacts of science and technology policy}

Some philosophers of technology have recently argued that science should move beyond a contractual relationship with society and join in the quest for the common good. In their view, the "good in science, just as in medicine, is integral to and finds its proper place in that overarching common good about which both scientists and citizens deliberate" (Mitcham \& Frodeman 2000). This view may sound attractive, but it fails to show how various communities with competing conceptions of the "good life" within modern societies could arrive at a consensus and how this could drive public (research) policy. Moreover, an Aristotelian conception of the good life is difficult to marry with a modern rights approach, whereby, for instance in the case of the European Union, the European Charter of Fundamental Rights provides a legitimate and actual basis for European public policy. Nonetheless, their point of departure remains challenging: "We philosophers believe that publicly funded scientists have a moral and political obligation to consider the broader effects of their research; to paraphrase Socrates, unexamined research is not worth funding" (Frodeman \& Holbrook 2007).

The US National Science Foundation makes assessment of proposals in terms of "broader impacts" in the framework of considering research proposals worth of funding. Under the European Framework Programmes for Research, there is a long tradition of awarding research grants, among other, on the basis of anticipated impacts. Indeed, already at the stage of evaluation of research proposals we are looking for particular impacts. Currently, expected impacts of research topics which are subject of public calls for proposals, are listed in the work programmes of 7 th Framework Programme. But what are legitimate normative assumptions to make these expected impacts, the right impacts allowing us to steer public research agenda's? We can't make an appeal to conceptions of

3 In addition, impacts, especially beyond their predefined risks, are increasingly ambiguous in nature, and cannot be easily framed in positive or negative impacts. At a global scale, one can even note clear "ethical divergence" among and within regions, for example when it comes to use of clinical trials, stem cell research etc. (Ozalina et al. 2009). 
the good life, but we can make an appeal to the normative targets which we can find in the Treaty on the European Union. These normative targets have been democratically agreed upon and, in fact, provide the legitimate basis for having a public framework progamme for research at the European level. From the Treaty on the European Union (in particular article 2) we can derive the following:

- "The Union shall (...) work for the sustainable development of Europe based on balanced economic growth and price stability, a highly competitive social market economy, aiming at full employment and social progress, and a high level of protection and improvement of the quality of the environment. It shall promote scientific and technological advance.

- It shall combat social exclusion and discrimination, and shall promote social justice and protection, equality between women and men, solidarity between generations and protection of the rights of the child.

- To promote (..) harmonious, balanced and sustainable development of economic activities, a high level of employment and of social protection, equality between men and women, sustainable and non-inflationary growth, a high degree of competitiveness and convergence of economic performance, a high level of protection and improvement of the quality of the environment, the raising of the standard of living and quality of life, and economic and social cohesion and solidarity among Member States."

Rather than pre-empting views and conceptions of the "good life", the European Treaty on the European Union thus provides us with normative anchor points. Those normative anchor points and their mutual relationship provide thus a legitimate basis for defining the type of impacts, or the "right" impacts of research and innovation should pursue.(see figurel below). There are ofcourse normative anchor points which have their impacts beyond the EU. A reflection on "solidarity" and promotion of Human Rights refer to possible implications for the use of technology. Benefit sharing from the use of technologies and the use of genetic resources should address particular technology divides and potential inherent injustice and be translated into international commitments (Schröder 2010). The subsequent question is how the normative anchor points are reflected (or neglected) in the development of technologies. A short historical perspective can shed some light on this question. 


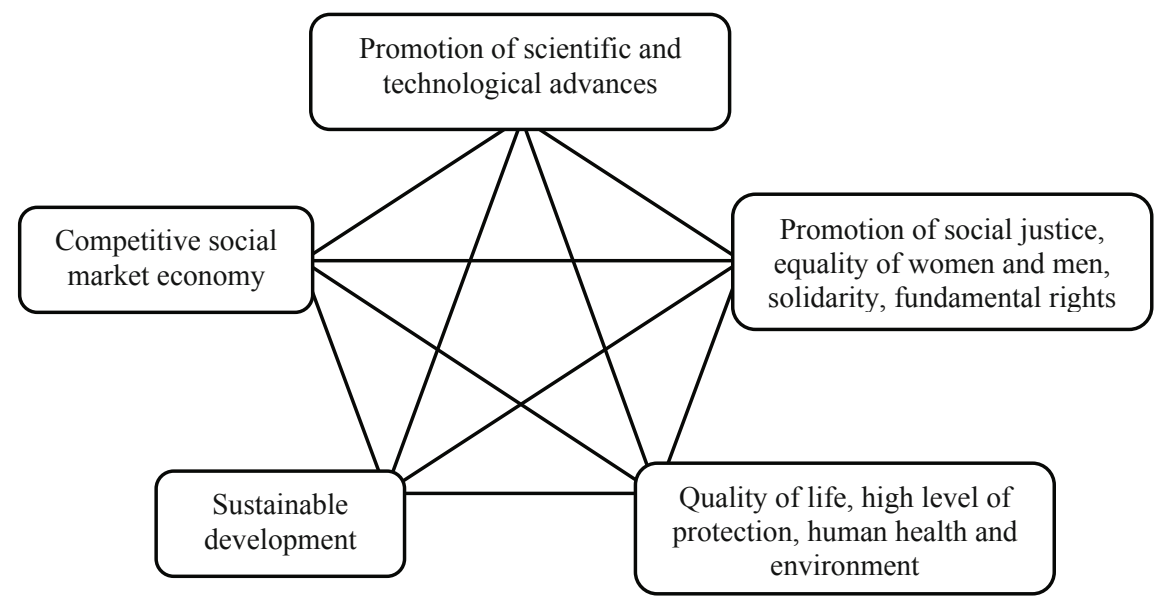

Figure 1: $\quad$ Normative anchor points derived from the Treaty on the European Union

\section{The responsible development of technologies: A historical perspective}

The formation of public opinion on new technologies is not a historically or geographically isolated process; rather, it is inevitably linked to prior (national and international) debate on similar topics. Ideally, such debates should enable a learning process - one that allows for the fact that public opinion forms within particular cultures and political systems. It is therefore not surprising that, in the case of relatively new technologies, such as nanotechnologies, the nature of public debate and its role in the policy making process is articulated against a background of previous discussion of the introduction of new technologies (such as biotechnology), or that specific national experiences with those technologies become important. In particular, the introduction of genetically modified organisms (GMOs) into the environment is a frequent reference point within Europe (whereas more frequently absent in such debates in the USA).

This historical development of policy frameworks can be followed through the ways in which terms are used and defined: initially, definitions are often determined by the use of analogies which, in the initial stages of the policy process, serve to 'normalise' new phenomena. In a number of countries, for instance, GMOs were initially regulated through laws which deal with toxic substances. Subsequently such analogies tend to lose their force as scientific 
insights on the technology grow and distinct regulatory responses can be made. GMOs, for example, eventually became internationally defined as 'potentially hazardous', and, in the European Union, a case by case approach was adopted under new forms of precautionary regulation. This framework was developed over a period of decades, and thereby took into account the ever-widening realm in which GMOs could have effects (developing from an exclusive focus on direct effects to eventually include indirect and long-term effects). It is not, however, solely the scientific validity of analogies which determines definitions and policy: public interest also plays an important role. Carbon dioxide, for instance, has changed from being viewed as a gas essential to life on earth to being a 'pollutant'. (The latest iteration of this evolution came just prior to the Copenhagen summit on climate change in December 2009, when the American Environmental Protection Agency defined greenhouse gases as a "threat to public health" - a definition which has important implications for future policy measures.)

In the case of relatively new or emerging technologies, such as nanotechnology policy, then, it seems likely that we are still in the initial phases of development. There are not, so far, any internationally agreed definitions relating to the technology (despite repeated announcements of their imminence), and nanoparticles continue to be defined as "chemical substances" under the European regulatory framework REACH. (Analogies are also made with asbestos, as a way to grasp hold of possible environmental and human health effects, but these are contested. There is no certainty that they will become the definitive way to frame risk assessments.) To cite one topical example, nanotechnology in food will not start its public and policy life with a historically blank canvas but will be defined as a 'novel food' under a proposal for renewing the Novel Foods regulation (The Novel Foods regulation came into existence in the 1990's with foods containing or consisting of GMO's in mind). Recent proposals for renewing regulation on food additives (after a first reading of the European Commission's proposal in the European Parliament in April 2009) have made this the first piece of regulation to include explicit reference to nanotechnology.

Public debate that articulates particular interests and scientific debate on the validity of analogical approaches to nanotechnologies will inevitably continue to shape the ways in which nanotechnologies are addressed in regulation and policy. But the governance of the technology, as well as debate around it, has to be seen within its historical context. How did stakeholders behave in previous cases, and what can we learn from these cases with regard to new technologies such as nanotechnologies? One answer to this question might point to a learning process around the governance of new technologies, and the development of a consensus that early involvement of both stakeholders and the broader public is of the utmost importance. The European Commission has responded to this with its adop- 
tion of a European strategy and action plan on nanotechnologies, which addresses topics from research needs to regulatory responses and ethical issues to the need for international dialogue. This strategy above all emphasizes the "safe, integrated and responsible" development of nanosciences and nanotechnologies - something which the European Research project "DEEPEN" has drawn upon in articulating how 'responsible development' might take its course within deliberative fora (MacNaghten et al. 2010).

We can conclude that the "safe, integrated and responsible" development gives us a new, overarching anchor point for making, for instance, nanotechnology policy. Obviously, this has to be built on the basic anchor points in the treaty, concerning "a high level of protection of the environment and human health", applying precaution etc..

These normative anchor points, in their mutual interdependency, should guide the impact assessments of technologies, and also the notion of desirable expected impacts of research. This brings us to how we can identify these "right" impacts of research and technologies. The use of foresight and ability to identify plausible outcomes becomes then indispensible.

\section{Identifying plausibility and use of foresight}

One can distinguish, within the thought tradition of Charles Sander Peirce, the plausibility of knowledge claims from the predictability of individual statements in the context of scientific discourse (von Schomberg 1993). For instance, I have characterized epistemic discussions in science as discussions triggered by controversies arising from the acquisition of new scientific knowledge, whereby scientific methods and the fundamental understanding of the nature of the subject matter often become subject to dispute themselves. In such cases, the authorities within scientific disciplines are mutually challenged in terms of which discipline can claim to offer the best solution to the problem in question. Recent examples of epistemic discussions in science include the debates between molecular biologists and ecologists on the risks of GMO's, the debate on climate change as either being induced by human interventions or as caused by natural cycles, and the debate between K. Eric Drexler and Richard Smalley on the plausibility of molecular nanotechnology and engineering.

Typically, epistemic discussions induce public debate long before any scientific closure on the issue is to be expected and provides a significant challenge for developing reasonable public policy. Which group of scientists can we believe and should we endorse? Plausible, epistemic approaches on the acquisition of knowledge in science are associated with problem-definitions, which in 
turn frame (although, often, only implicitly) policy approaches. Unidentified and unacknowledged epistemic debate can result in unbalanced public policy: the until recently not uncommon "wait and see" character of public policies of nation states on climate change or the concentration on the promises and blessings of all kinds of new technologies provide examples whereby public policy takes sides prematurely in a scientific debate that is still unfolding.

It is therefore of utmost importance to be able to identify such epistemic discourses and knowledge gaps within the various plausible options on the table in order to be able to have a more robust outlook on potential technological solutions - and in order to keep open the possibility for alternative developments. Foresight projects can make a contribution towards the possibility that alternative developments might remain in sight for possible public policy responses and towards enabling democratic choices at early stages of technological development. The use of foresight projects can help us to overcome the often too narrowly conceived problem definition scientists implicitly work with (Karinen \& Guston 2010). Social scientists could do some heuristic work by spelling out these problem definitions. For example, an imaginary nanotechnology enabled product of a "disease detector" (a device which would enable disease detections before symptoms emerge) is probably based on a problem definition that it is a medical imperative that any "disease" needs to be identified, irrespective of available treatment and irrespective whether the individual in question would define himself or herself as ill and possibly sidetracks preventive approaches adopting particular lifestyles. Moreover, problem definitions scientists implicitly work with often correspond to a centuries old, general standard list of fundamental human needs (which represent overarching problem definitions) to which new technologies will presumably provide answers in a given future: food and energy supply, human health, security and since a half a century also "the environment". The case of recent technologies such as nanotechnology is in no way different, especially if one considers the public reasons for its funding. Because of its enabling and diverse character, it would open a future with very efficient solar energy, nanorobots cleaning our blood vessels, water sanitation solutions for the "third world", etc..

The link between options, which may only look plausible at a particular stage of development in science and technology, and particular ways of social problem solving, is a perplexing one. For instance, it seems obvious that our world food problem is principally not a technological problem but a politicaleconomic distribution problem. Yet, the increase of land use for biofuels may well cause a situation whereby a political-economic solution could become increasingly less likely, if not impossible, before it ever arrived at a (world) policy level in a historic time period in which this type of solution still was an 
option. Putting our attention - and with it our hopes and/or fears - primarily on an accelerated form of innovation by (nano-)technological means is therefore irresponsible.

In order to help mitigate this, foresight projects could benefit from a prior analysis of potential relationships between types of plausible technological pathways and particular (social) problem-definitions, rather than starting with "naïve product scenes," which are, as Selin outlines them, "short vignettes that describe in technical detail, much like technical sales literature, a nano-enabled product of the future" (Selin 2009, p. 5) thereby methodologically ignoring the underlying problem definitions. It is also important to make an analysis of the linkages between technological pathways and social problem definitions and how they may well get the support of particular stakeholders or give a boost to particular ideologies within public policies. A process of "negotiating plausibility" eventually means reaching consensus on such problem definitions. Minimally, we could help to avoid continually funding developments which are later shown to be fictious; but more constructively, we could create deliberative forms of decision making on the problem definitions themselves and place them in a wider perspective.

\section{Deliberative approaches to the policy making process}

Public engagement projects such as the Nanofutures ${ }^{4}$ or the Nanosec project ${ }^{5}$ adopts both a foresight and a deliberative approach, which is to be welcomed. It is, however, important to note that the reason for this approach is not limited to the normative rationale of a more democratic and transparent decision making process. The deliberative foresight approach can also improve the quality of the decision making process and help to identify knowledge gaps for which we would need to go back to science. A part of this potential "quality" gain gets lost when we limit deliberation to stakeholder or public deliberation, although these constitute necessary components. An immediate normative deficiency of stakeholder deliberation is that the involved actors do not necessarily include the

4 A project conducted by the Center for Nanotechnology in Society at Arizona State University http://cns.asu.edu/program/rtta3.htm

5 Nanotechnologies for tomorrow's society' (nanosoc): The nanosoc research consortium seeks to understand and address these issues by calling for an early and informed dialogue between nanotechnology researchers, social scientists, technology assessment experts, industry representatives, policy makers, non-governmental agencies, and interested citizens in Flanders, Belgium. http://www.nanosoc.be/ResearchDesign-en.asp 
interest of non-included actors. That said, foresight exercises need to be progressively embedded in public policy in order to make a real qualitative step forward. We cannot rely on stakeholder and or public deliberation as such, since epistemic debate in science is immediately mirrored by stakeholder and public dissent in society. Policy makers are equally challenged by dissent in science as by dissent among stakeholders and the public. If we deal unreflexively with public debate induced by epistemic debate, an improper politicising effect inevitably occurs and translates into an irrational struggle concerning the "right" data and the "most trustful and authoritative scientists" in the political arena. Interest groups can pick and choose the experts which share their political objectives. A functional deliberative approach, apart from public and stakeholder deliberation, includes a deliberative extension of the science-policy interface. Such an interface institutionalises particular deliberation based on normative filters such as notions of proportionality and precaution (or as we have in the EU, the requirement to implement the precautionary principle in policy frameworks), various forms of impact analysis, such as sustainability impacts, cost-benefit analysis, environmental policy impact analysis etc., the application of particular consensual norms or prioritisation of norms (for instance that health and environment takes precedence over economic considerations) and the application of normative standards for product acceptability. These normative filters are in themselves results of public and policy deliberation and enable consensual decision making at the public policy level. Although democratic societies have these deliberative filters in place, they need to be consciously applied and be subject of public monitoring. Currently I see a procedural gap, especially, when it comes to identification of knowledge gaps and the assessment of the quality of the available knowledge. I have, therefore, argued for a deliberative form of "knowledge assessment" at the science-policy interface to allow for a qualified knowledge input (Von Schomberg 2007).

Moreover, in the context of scientific uncertainty and production of knowledge by a range of different actors, we need knowledge assessment mechanisms which will assess the quality of available knowledge for the policy process. We are currently forced to act upon developments (in terms of public policy) while at the same time being uncertain about the quality and comprehensiveness of the available scientific knowledge and the status of public consensus. A deliberative approach to the policy-making process would complement and connect with deliberative mechanisms outside policy. The outcomes of ongoing knowledge assessment (Von Schomberg 2007, Von Schomberg et al. 2005) should feed into other assessment mechanisms and into deliberation on the acceptability of risk, the choice of regulatory frameworks or the measures taken under those frameworks (see figure 2). Knowledge assessment following the result of foresight 
exercises would then be important tools in setting out arguments for the necessity and nature of future legislative actions.

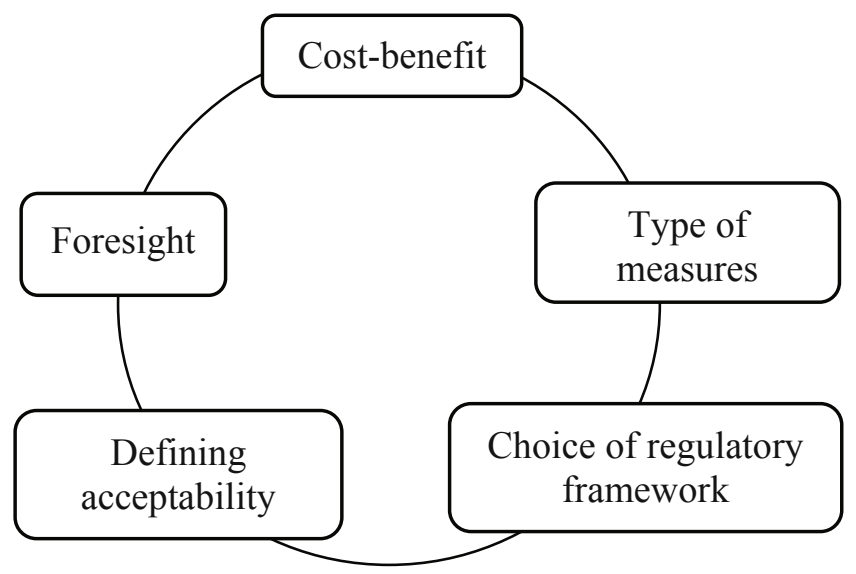

Figure 2: $\quad$ A non-directional cycle of assessment mechanisms within the policy making process fed by knowledge assessment processes.

At the same time, we have to ensure that science policies are consistent with other public policies: The challenge is not only to focus on the conditions for good and credible science ${ }^{6}$, but to make knowledge production, dissemination and use a key factor for virtually all public policy goals. Both impact assessments and assessments of expected impacts of research should reflect this. In the following section I will describe the necessary elements for a framework for responsible research and innovation which systematically takes up the quest for "the right impacts".

6 The development of codes of conduct concerning "scientific integrity" has received attention over the recent years in the aftermath of various high profile cases of 'scientific fraude'. Although this is important, issues of integrity belong in my view to the normal good practice of science and are not a specific issue for responsible research and innovation. Equally, the establishment of "open access" to research outcomes is a precondition for fostering scientific innovative practices rather than specific for responsible research and innovation. 


\section{Responsible research and innovation}

I propose the following working definition for responsible research and innovation: Responsible research and innovation is a transparent, interactive process by which societal actors and innovators become mutually responsive to each other with a view on the (ethical) acceptability, sustainability and societal desirability of the innovation process and its marketable products (in order to allow a proper embedding of scientific and technological advances in our society).

There is a significant time lag (this can be several decades) between the occurrence of technical inventions (or planned promising research) and the eventual marketing of products resulting from RTD and innovation processes. The societal impacts of scientific and technological advances are difficult to predict. Even major technological advances such as the use of the internet and the partial failure of the introduction of GMOs in Europe have not been anticipated by governing bodies. Early societal intervention in the research and innovation process can help to avoid that technologies fail to embed in society and or help that their positive and negative impacts are better governed and exploited at a much earlier stage. I see two interrelated dimensions: the product dimension, capturing products in terms of overarching and specific normative anchor points and a process dimension reflecting a deliberative democracy:

\section{Product dimension}

Products which are marketed throughout a transparent process should thus be evaluated and designed with a view on their normative anchor points:

- (Ethically) acceptable: refers to a mandatory compliance with the fundamental values of the EU charter on fundamental rights (right for privacy etc.) and the safety protection level set by the EU. This may sound obvious, but the practice of implementing ICT technologies has already demonstrated in various cases the neglectance of the fundamental right for privacy and data protection. It also refers to the "safety" of products in terms of acceptable risks. It goes without saying that ongoing risk assessments is part of the procedure towards acceptable products when safety issues are concerned. However, also in this case the issue of safety should be taken in a broader perspective. The United Kingdom's largest public funder of basic innovation research, the Engineering and Physical Science and Research Council has asked applicants to report the wider implications and potential risks (environmental, health, societal and ethical) (Owen \& Goldberg 2010). Often, the 
risks related to new technologies, can neither be quantified nor a normative baseline of acceptability can be assumed by scientists as if such a particular assumed baseline would represent the baseline of societal acceptance.

- Sustainable: contributing to the EU's objective of sustainable development. The EU follows the 1997 UN "definition" of sustainable development, consisting of economic, social and environmental dimension in their mutual dependency. This overarching anchor point can become further materialized under the following overarching anchor point:

- Socially desirable: "socially desirable" captures here the relevant, and more specific normative anchor points in the Treaty on the European Union, such as "quality of life", "equality among men and women" etc.. It has to be noted that a systematic inclusion of these anchor points in product development and evaluation, would go clearly beyond simple market profitability, although the latter could work out as a precondition for the products' viability in market competitive economies. However, it would be consistent with the EU treaty to promote such product development through financing RTD actions. In other words, at this point responsible research and innovation would not need any new policy guidelines, but simply would require a consistent application of the EU's fundamentals to the research and innovation process reflected in the Treaty on the European Union ${ }^{7}$. We have, up till recently, possibly assumed that those values cannot be applied in the context of research and innovation.

\section{Deployment of Methods}

1. Use of technology assessment and technology foresight in order to anticipate positive and negative impacts or, whenever possible, define desirable impacts of research and innovation both in terms of impact on consumers and communities. Setting of research priorities with their anticipated impacts need to be subjected to a societal review. This implies broadening the review of research proposals

Various top officials of the European Institutions refer to common European values for promoting particular public policies. It seems to me that this could also be applied the type of Research outcomes we wish to achieve with European Public Funds. Note the following quotes: "The defence of human rights and a justice system based on the full respect of human dignity is a key part of our shared European values", Jerzy Buzek, European Parliament President, 10 October, 2009; "Europe is a community of Values", Van Rompuy, First European Council President, 19 November 2009; "My political guidelines for the Commission's next mandate stress the idea that Europe's actions must be based on its values", President Barroso, European values in the new global governance, 14 October 2009. 
beyond scientific excellence and including societal impacts. ${ }^{8}$ Particular technology assessment methods also help to identify societal desirable product by addressing the normative anchor points throughout their development. Methodologies to further precise and "script" the future expected impacts of research should be developed (Den Boer et al. 2009). A good example from the field of synthetic biology give Marc Bedau et al. (2009) who have identified six key checkpoints in protocell development (e.g. cells produced from non-living components by means of synthetic biology) at which particular attention should be given to specific ethical, social and regulatory issues, and made ten recommendations for responsible protocell science that are tied to the achievement of these checkpoints.

The advantage is that technology assessment and technology foresight can reduce the human cost of trial and error and make advantage of a societal learning process of stakeholders and technical innovators. It creates a possibility for anticipatory governance. This will ultimately lead to products which are (more) societal robust.

\section{Application of Precautionary Principle}

The precautionary principle is embedded in EU law and applies especially within EU product authorization procedures (e.g. REACH, GMO directives etc.). The precautionary principle works as an incentive to make safe and sustainable products and allow governmental bodies to intervene with risk management decisions (such as temporary licensing, case for case decision making etc.) whenever necessary in order to avoid negative impacts.

As argued above, the responsible development of new technologies must be viewed in its historical context. Some governance principles have been inherited from previous cases: this is particularly notable for the application of the precautionary principle to the field of nanosciences and nanotechnologies. This principle is firmly embedded in European policy, and is enshrined in the 1992 Maastricht Treaty as one of the three principles upon which all environmental policy is based. It has been progressively applied to other fields of policy, including food safety, trade and research.

The principle runs through legislation that is applied to nanotechnologies, for example in the 'no data, no market' principle of the REACH directive for

8 The Netherlands Organisation for Scientific Research (NWO) has developed a research funding programme on Responsible Innovation under which research proposals are subject to a review in terms of societal relevance. See: http://www.nwo.nl/nwohome.nsf/pages/ NWOA_7E2EZG_Eng 
chemical substances, or the pre-market reviews required by the Novel Foods regulation as well as the directive on the deliberate release of GMOs into the environment. More generally, within the context of the general principles and requirements of the European food law it is acknowledges that "scientific risk assessment alone cannot provide the full basis for risk management decisions" leaving open the possibility of risk management decision making partly based on ethical principles or particular consumer interests.

In the European Commission's recommendation on a code of conduct for nanosciences and nanotechnologies research, the principle appears in the call for risk assessment before any public funding of research (a strategy currently applied in the 7th Framework Programme for research). Rather than stifling research and innovation, the precautionary principle acts within the code of conduct as a focus for action, in that it calls for funding for the development of risk methodologies, the execution of risk research, and the active identification of knowledge gaps. Under the Framework Programme, for example, an observatory has been funded to create a network for the communication and monitoring of risk.

\section{Use of demonstration projects: moving from risk to innovation governance}

These projects should bring together actors from industry, civil society and research to jointly define an implementation plan for the responsible development of a particular product to be developed within a specific research/innovation field, such as information and communication technology or nanotechnology. Responsible innovation should be materialised in terms of the research and innovation process as well as in terms of (product) outcomes. The advantage is that actors can not exclusively focus on particular aspects (for instance, civil society organizations addressing only the risk aspects) but have to take a position on the innovation process as such. Thus allowing a process to go beyond risk governance and move to innovation governance. The company BASF, for example, has established a dialogue forum with civil society organizations and also developed a code of conduct for the development of new products. ${ }^{10}$

9 Regulation (EC) no. 178/2002 of the European Parliament and of the Council of 28 January 2002 laying down the general principles and requirements of food law, establishing the European Food Safety Authority and laying down procedures in matters of food safety states "it is recognised that scientific risk assessment alone cannot, in some cases, provide all the information on which a risk management decision should be based, and that other factors relevant to the matter under consideration should legitimately be taken into account including societal, economic, traditional, ethical and environmental factors and the feasibility of controls".

10 In the BASF Dialogueforum Nano representatives of environmental and consumer organisations, trade unions, scientific institutes and churches (civil society organisations / non governmental organisations) work together with employees of the chemical company BASF SE on 


\section{Process dimension}

The challenge is to arrive at a more responsive, adaptive and integrated management of the innovation process. A multidisciplinary approach with the involvement of stakeholders and other interested parties should lead to an inclusive innovation process whereby technical innovators become responsive to societal needs and societal actors become co-responsible for the innovation process by a constructive input in terms of defining societal desirable products.

\section{Deployment of methods}

\section{Deployment of codes of conduct for research and innovation: Organizing} collective co-responsibility

Codes of conduct in contrast to regulatory interventions allow a constructive steering of the innovation process. It enables the establishment of a proactive scientific community which identifies and reports to public authorities on risks and benefits in an early stage. Codes of conduct are particular useful when risks are uncertain and when there is uncertain ground for legislative action (nanotechnology for example). Codes of conduct also help to identify knowledge gaps and direct research funds towards societal objectives.

Policy development treads a fine line: Governments should not make the mistake of responding too early to a technology, and failing to adequately address its nature, or of acting too late, and thereby missing the opportunity to intervene. A good governance approach, then, might be one which allows flexibility in responding to new developments. After a regulatory review in 2008, the European Commission came to the conclusion that there is no immediate need for new legislation on nanotechnology, and that adequate responses can be developed - especially with regard to risk assessment - by adapting existing legislation. ${ }^{11}$

While, in the absence of a clear consensus on definitions, the preparation of new nano-specific measures will be difficult and although there continues to be significant scientific uncertainty on the nature of the risks involved, good governance will have to go beyond policy making focused on legislative action. The

various issues related to the subject of nanotechnologies. See for a recent report: http://www.risiko-dialog.ch/component/content/article/507-basf-dialogueforum-nano-finalreport-2009-2010

11 However, the European Commission will give follow-up to the request of the European Parliament to review all relevant legislation within a period of two years, to ensure safety over the whole life cycle of nanomaterials in products. 
power of governments is arguably limited by their dependence on the insights and cooperation of societal actors when it comes to the governance of new technologies: the development of a code of conduct, then, is one of their few options for intervening in a timely and responsible manner. The Commission states in the second implementation report on the action plan for Nanotechnologies that "its effective implementation requires an efficient structure and coordination, and regular consultation with the Member States and all stakeholders" (Commission of the European Communities 2009, p. 10). Similarly, legislators are dependent on scientists' proactive involvement in communicating possible risks of nanomaterials, and must steer clear of any legislative actions which might restrict scientific communication and reporting on risk. The ideal is a situation in which all the actors involved communicate and collaborate. The philosophy behind the European Commission's code of conduct, then, is precisely to support and promote active and inclusive governance and communication. It assigns responsibilities to actors beyond governments, and promotes these actors' active involvement against the backdrop of a set of basic and widely shared principles of governance and ethics. Through codes of conduct, governments can allocate tasks and roles to all actors involved in technological development, thereby organising collective responsibility for the field. ${ }^{12}$ Similarly, Mantovani et al. (2010) propose a governance plan which both makes use of existing governance structures and suggests new ones, as well as proposing how they should relate to each other.

The European Commissions' recommendation on a code of conduct also views Member States of the European Union as responsible actors, and invites them to use the code as an instrument to encourage dialogue amongst "policy makers, researchers, industry, ethics committees, civil society organisations and society at large" (recommendation number 8 to Member States, cited on page 6 of the Commission's recommendation), as well as to share experiences and to review the code at the European level on a biannual basis. It should be considered that such codes of conduct would in the future extend its scope beyond research and also address the innovation process. ${ }^{13}$

12 Collective co-responsibility accounts for the fact that technological impacts are impacts of collective actions and can not be traced back to merely individual responsibility (See for an extensive argument: Von Schomberg 2007. The code of conduct, the European Commission recommends to the Member States of the EU reflects an attempt to organise collective co-responsibility in the case of nanotechnologies (Commission of the European Communities 2008).

13 The European Project NANOCODE makes this point concerning nanosciences and nanotechnologies, see: http://www.nanocode.eu/ 


\section{Ensuring market accountability: Use of standards, certification and accredita-} tion schemes and labels

The adoption of standards and even "definitions" are fundamental requirements to allow for a responsible development. The outstanding adoption of a definition for nanoparticles, for example makes legislation and adequate labeling practices difficult, if not impossible. Lawrence Bush (2010) notes that the use of standards, certifications and accreditations constitute a new form of governance which progressively has replaced and transmuted positive law, as a product of the state, with its market equivalent. Although this form of governance is in need of improvement, we unavoidably have to make productive use of it, as the flood of products and processes coming on the market will not be manageable only through governmental bodies and agencies. Yet, the perception and working in practice of these standards is significant. For example, in 2005, it was claimed that the EU had forced local authorities to remove see-saws from children's playgrounds. In fact, there were no EU measures in this area at all. There are some standards set by the European Committee for Standardisation (CEN), a voluntary organisation made of national standards bodies. These sought to limit the height from which children could fall, by specifying the maximum height for seats and stands, and by fixing standards for hand supports and footrests. Manufacturers could choose whether to follow these standards, which carried the advantage of being able to export across Europe, instead of having to apply for certification in each country. ${ }^{14}$

The area of data- and privacy protection in the context of the use of ICT and security technologies should also be impacted by forms of self-regulation and standard setting. Data controllers based at operators need to provide accountability, which can be termed as a form of verifiable responsibility (Guagnin et al. 2010). Crucial will be the involvement of third parties which can implement, minimally, a transparent verification practice. In other fields, the whole certification can be done by a third party. For example, in 1996 the World Wildlife Fund (WWF) and Unilever have joined forces and collectively constructed a long-term programme for sustainable fishery. They have founded an independent non-profit organisation to foster worldwide fishery. At the same time they apply "standards of sustainable fishing" which is also monitored by independent certifying agencies to control those standards.

Standards will also need to reflect particular ethical considerations and go well beyond mere technical safety issues. Currently, the development of new ISO standards for nanofood may involve the inclusion of ethical standards (Forsberg 2010). 


\section{Ethics as a "design" factor of technology and increasing social-ethical reflexivity in research practices}

Ethics should not be seen as being only a constraint of technological advances. Incorporating ethical principles in the design process of technology can lead to well accepted technological advances. For instance, in Europe, the employment of body imaging technology at airports has raised constitutional concerns in, among others, Germany. It has been found to be doubtful whether the introduction is proportional to the objectives being pursued. The introduction of a "smart meter" at the homes of people in the Netherlands to allow for detection of and optimalisation of energy use, was rejected on privacy grounds, as it would have possibly allowed third parties to monitor whether people are actually in their homes. These concerns could have been avoided if societal actors would have been involved in the design of technology early on. "Privacy by design" has become a good counter example in the field of ICT by which technology is designed with a view on taking privacy as a design principle of the technology itself, into account. Yet, practicing it, is still rare. The European project ETICA ${ }^{15}$ has recommended the introduction of specific governance structures for emerging (ICT) technologies.

Recently "midstream modulation" (Fisher et al. 2006, Fisher 2007) has emerged a promising approach to increase social-ethical reflexivity within research practices. In the form of laboratory engagement practices, social scientists and/or ethicists are embedded in research teams of natural scientists. The embedded social scientist engages natural scientists on the wider impact of their work, while doing research in the laboratories. Reports from these practices could feed into schemes on responsible research and innovation.

4. Deliberative mechanisms for allowing feedback with policymakers: Devise models for responsible governance

Continuous feed back from information generated in technology assessment, technology foresight and demonstration projects to policy makers could allow for a productive innovation cycle.

In addition, as outlined above, "knowledge assessment" procedures have to be developed in order to allow assessing the quality of information within the policy process, especially in areas in which scientific assessments contradict each other or in cases of serious knowledge gaps. (The EC practices this partly with its impact assessments for legislative actions). Knowledge assessment would integrate the distinct cost-benefit analysis, environmental and sustainability impact assessments). In short: models of responsible governance have to 
be devised which allocates roles of responsibility to all actors involved in the innovation process. Ideally, this should lead to a situation in which actors can resolve conflicts and go beyond their traditional roles: companies addressing the benefits and non-governmental organisations the risks. Co-reponsibility implies here that actors have to become mutually responsive, thus companies adopting a perspective allow to go beyond immediate market competiveness and NGOs reflecting on the constructive role of new technologies for sustainable product development. In this context, technology assessment, as practiced, for example, by the Dutch Rathenau Insitute, can take up the function of "seducing actors to get involved and act" (Van Est 2010).

\section{Public debate: Moderating "policy pull" and "technology push"}

Ongoing public debate and monitoring of public opinion is needed for the legitimacy of research funding and particular scientific and technological advance. Ongoing public platforms should replace one-off public engagement activities with a particular technology and, ideally, a link with the policy process should be established. The function of public debate in viable democracies includes enabling policy makers to exercise agenda and priority setting. Public debate, ideally, has a moderating impact on "technology push" and "policy pull" of new technologies. Technology push has occurred in the European Union with the hope of operators to accomplish a fait accompli with the market introduction of genetically modified soya in the mid 1990s. Environmental groups, notably Greenpeace which did not mention GMOs as an environmental concern prior to their introduction on the market, responded with an outright rejection. Technology push as product-acceptance strategy does not work. At the other extreme, we can notice a strong policy pull concerning the introduction of security technologies such as the use of biometrics for passports and asylum applications and whole body image technology (colloquial: "body scanner") at airports. Politicians and policy makers have been eager to accept and promote the implementation of those technologies, sometimes beyond their technical feasibility. Impact assessments should consist of a proportionality analysis whether particular measures and, potential infringement of privacy and data protection are proportional with a view on possible legitimate objectives for implementing security technologies. However, both "technical safety" and the determination of proportionality can not be fully left to scientist or, in case of proportionality, to legal experts. Both cases assume normative baselines for acceptable risks or acceptable infringements of privacy rights. These baselines should be subject to public debate. 


\begin{tabular}{|l|l|}
\hline \multicolumn{2}{|c|}{ Features of responsible research and innovation } \\
\hline \multicolumn{1}{|c|}{$\begin{array}{c}\text { Product dimension: } \\
\text { addressing normative anchor points }\end{array}$} & \multicolumn{1}{c|}{$\begin{array}{c}\text { Process dimension: } \\
\text { deliberative democracy }\end{array}$} \\
\hline - $\begin{array}{l}\text { Institutionalisation of technology } \\
\text { assessment and foresight }\end{array}$ & - $\begin{array}{l}\text { Use of code of conducts } \\
\text { Ensuring market accountability: Use } \\
\text { of standards, certification schemes, } \\
\text { Application of the precautionary } \\
\text { principle, ongoing risk assessment, } \\
\text { ongoing monitoring }\end{array}$ \\
$\begin{array}{l}\text { Use of demonstration projects: from } \\
\text { risk to innovation governance }\end{array}$ & - $\begin{array}{l}\text { Ethics as a design principle for } \\
\text { technology }\end{array}$ \\
& - $\begin{array}{l}\text { Normative models for governance } \\
\text { Ongoing public debate: Moderating } \\
\text { "policy pull" and "technology push" }\end{array}$ \\
\hline
\end{tabular}

Figure 3: Overview on features of responsible research and innovation

\section{Conclusion}

I see the prospects of technology assessment in a context of a policy pull for more and improved assessments of the impacts of research and innovation processes. This policy pull will increasingly occur for economic, social and environmental reasons. The economic reason is obvious. The public funds which go to research and innovation have to pay off in terms of intended and societal beneficial impacts. Yet the quest for assessing and foreseeing these impacts gives us the opportunity to define those impacts along the same three pillars of the United Nations objective of sustainable development (economic, social and environmental) with a view on fundamental normative anchor points on which there is a broad consensus. This provides an outlook on how responsible research and innovation can be designed in research terms and framed in policy terms. The trend to merge technology assessments with other assessments will thus need to continue. At the same time, a further institutionalization of technology assessment is necessary to provide the possibility for the timely availability of impact assessments and as a tool for early societal intervention in research and innovation processes. It would also need to appear more systematically as a required field of study in the curricula of science and engineering students. 


\section{Literature}

Bush, L. (2010): Standards, Law and Governance. Journal of Rural Social Sciences 25(3), pp. 56-78

Bedau, M.; Parke, E.; Tangen, U. et al. (2009): Social and ethical checkpoints for bottomup synthetic biology, or protocells. Syst Synth Biol (2009) 3, pp. 65-75

Commission of the European Communities (2009): Communication from the commission to the council, the European Parliament and the European Economic and Social Committee. Nanosciences and Nanotechnologies: An action plan for Europe 20052009. Second Implementation Report 2007-2009, Brussels, 29.10.2009, COM (2009) 607 final

Commission of the European Communities (2008): Commission Recommendation of 7 February 2008, on a code of conduct for responsible nanosciences and nanotechnologies research, 7 February 2008

European Communities (2006): Better Regulation. Simply explained. Luxembourg: Office for Official Publications of the European Communities

den Boer, D.; Rip, A. \& Speller, S. (2009): Scripting possible futures of nanotechnologies: A methodology that enhances reflexivity in: Technology in Society 31 (2009), pp. 295-304

Forsberg, E. (2010): Safe and socially robust development of nanofood through ISO standards? In: Romeo Casabona, C.; Escajedo San Epifanio, L. \& Emaldi Cirión, A. (eds.): Global food security: ethical and legal challenges. Wageningen: Academic Publishers

Frodeman, R. \& Holbrook, B. (2007): Science's Social Effects. Issues in Science and Technology, Spring 2007

Fisher, E.; Mahajan, R. \& Mitcham, C. (2006): Midstream Modulation of Technology: Governance from Within. Bulletin of Science, Technology \& Society 26(6), pp. 485-496

Fisher, E. (2007): Ethnographic Invention: Probing the Capacity of Laboratory Decisions. NanoEthics 1(2), pp. 155-165

Grunwald, A. (2010): Technikfolgenabschätzung - Eine Einführung. 2. überarb. Auflage. Berlin: Edition Sigma

Guagnin, D.; Hempel, L. \& Ilten, C. (2011): Privacy Practices and the Claim for Accountability. In: von Schomberg, R. (ed.): Towards Responsible Research and Innovation in the Information and Communication Technologies and Security Technologies Fields. Luxembourg: Publication Office of the European Union, forthcoming

Karinen, R. \& Guston, D. (2010): Towards Anticipatory Governance. The Experience with Nanotechnology. In: Kaiser, M. (eds): Governing Future Technologies. Nanotechnology and the Rise of an Assessment Regime. : Dordrecht, Heidelberg, London, New York: Springer

MacNaghten, P.; Davies, S. \& Kearnes, M. (2010): Narrative and Public Engagement. Some findings from the Deepen-Project. In: von Schomberg, R. \& Davies, S. (eds.): Understanding public debate on nanotechnologies. Options for Framing Public Policy. Luxembourg: Publication office of the European Union 
Mantovani E. \& Procari, A. (2010): A Governance Platform to secure the Responsible Development of Nanotechnologies: the FramingNano project. In: von Schomberg, R. \& Davies, S. (eds.): Understanding Public Debate on Nanotechnologies. Options for Framing Public Policy. Luxembourg: Publication office of the European Union

Mitcham, C. \& Frodeman, R. (2000): Beyond the Social Contract Myth: Science should move beyond a contractual relationship with society and join in the quest for the common good. In: Issue in Science and Technology Online. Summer 2000

Owen, R. \& Goldberg, N. (2010): Responsible Innovation. A pilot study with the UK Engineering and Physical Science and Research Council. In: Risk Analysis 30(11), p. 1699

Ozalina, Z. et al. (2009): Global Governance of Science, Report of the Expert Group chaired by Zaneta Ozalina, Luxembourg: Office for Official Publications of the European Communities

Selin, C. (2009): Negotiating Plausibility: Intervening in the Future of Nanotechnology, Arizona State University, http://www.cspo.org/projects/plausibility/files/read Selin-Negotiating-Plausibilty.pdf

Schröder, D. (2010): European Project GENBENEFIT, http://www.uclan.ac.uk/schools/ school_of health/research_projects/genbenefit.php

Van Est (2010): From techno-talk to social reflection and action. Lessons from public participation in converging Technologies, International workshop "Deliberating converging technologies", IÖW, Berlin, 25-26 November 2010

Von Schomberg, R. (2007): From the ethics of technology towards and ethics of knowledge policy. Working document of the Service of the European Commission: http://ec.europa.eu/research/science-society/pdf/ethicsofknowledgepolicy_en.pdf

Von Schomberg, R.; Guimaraes Pereira, A. \& Funtowicz, S. (2005): Deliberating Foresight Knowledge for Policy and Foresight Knowledge Assessment, Working document of the European Commission Services

Von Schomberg, R. (ed.) (1993): "Controversies and Political Decision Making." Science, Politics and Morality: Scientific Uncertainty and Decision Making, Dordrecht: Kluwer Academic Publishers 